\title{
Supramolecular structure of enterobacterial wild-type lipopolysaccharides (LPS), fractions thereof, and their neutralization by Pep19-2.5
}

\author{
Klaus Brandenburg ${ }^{1}$, Lena Heinbockel ${ }^{2}$,Wilmar Correa ${ }^{1}$, Satoshi \\ Fukuoka $^{4}$, Thomas Gutsmann ${ }^{1}$, Ulrich Zähringer ${ }^{3}$, and Michel H.J. Koch ${ }^{5}$
}

Forschungszentrum Borstel, LG Biophysik ${ }^{1}$, Bioanalytische Chemie $^{3}$ und Experimentelle Pathologie ${ }^{2}$, D- 23845 Borstel, Germany ${ }^{4}$ National Institute of Advanced Industrial Science and Technology AIST, Takamatsu,Japan

${ }^{5}$ European Molecular Biology Laboratory, Hamburg Outstation, EMBL c/o DESY, Notkestr. 85, 22603 Hamburg, Germany

${ }^{*}$ Correspondence to K. Brandenburg

Forschungzentrum Borstel, Parkallee 10, D-23845 Borstel, Germany

E-mail: kbrandenburg@fz-borstel.de, Tel: +49-4537-1882350, Fax: +49-45371886320

Abbreviations: LPS lipopolysaccharide, SALP synthetic anti-LPS peptides, SAXS small-angle X-ray scattering

\section{Abstract}


Lipopolysaccharides (LPS) belong to the strongest immune-modulating compounds known in nature, and are often described as pathogen-associated molecular patterns (PAMPs). In particular, at higher concentrations they are responsible for sepsis and the septic shock syndrome associated with high lethality. Since most data are indicative that LPS aggregates are the bioactive units, their supramolecular structures are considered to be of outmost relevance for deciphering the molecular mechanisms of its bioactivity. So far, however, most of the data available addressing this issue, were published only for the lipid part (lipid A) and the core-oligosaccharide containing rough LPS, representing the bioactive unit. By contrast, it is well known that most of the LPS specimen identified in natural habitats contain the smooth-form (S-form) LPS, which carry additionally a high-molecular polysaccharide (O-chain). To fill this lacuna and going into a more natural system, here various wild-type (smooth form) LPS including also some LPS fractions were investigated by small-angle X-ray scattering with synchrotron radiation to analyze their aggregate structure. Furthermore, the influence of a recently designed synthetic anti-LPS peptide (SALP) Pep19-2.5 on the aggregate structure, on the binding thermodynamics, and on the cytokine-inducing activity of LPS were characterized, showing defined aggregate changes, high affinity binding and inhibition of cytokine secretion. The data obtained are suitable to refine our view on the preferences of LPS for non-lamellar structures, representing the highest bioactive forms which can be significantly influenced by the binding with neutralizing peptides such as Pep19-2.5.

KeywordsLIpopolysaccharides, SAXS, Antimicrobial peptides, Cytokines, Endotoxic conformation.

\section{Introduction}

Lipopolysaccharides (LPS) are major amphiphilic components of the outer membrane of Gram-negative bacteria. Beside their function as outer membrane 
barrier they represent important factors of pathogenicity in Gram-negative infections and, thus, are called endotoxins (1). Chemically, LPS are composed of a highly conserved lipid moiety, termed lipid $\mathrm{A}$, a core oligosaccharide the structural variability of which is limited within many species of an enterobacterial genus, and a more or less long polysaccharide (O-specific chain, $\mathrm{O}$ antigen) consisting of repeating units of, for example, a pentasaccharide (2), which is highly variable between different bacterial strains.

The biological activity of endotoxins was found to result exclusively from the lipid A portion, which therefore is called the 'endotoxic principle' of LPS (3).

There is a wealth of evidence that the physico-chemical characteristics of endotoxins in physiological fluids, i.e., at high water content, play an important role for the ability of these molecules to express biological activity. An important physical parameter is in particular the three-dimensional supramolecular structure of endotoxin aggregates (4),(5). Thus, for example, in previous investigations it was found that for free lipid A and various mutant LPS from Salmonella Minnesota and Escherichia coli the compounds with the shortest sugar chains (free lipid A, LPS Re and Rd) had a strong tendency to adopt cubic inverted structures already below $T_{c}$, the temperature of the gel to liquid crystalline phase transition, whereas all other rough mutant LPS exhibited these inverted structures - if at all - only above their $T_{c}$ lying at 30 to $36{ }^{\circ} \mathrm{C}$ for the different mutant and wild-type LPS (6-8). Most importantly, however, undert near physiological temperature $\left(37^{\circ} \mathrm{C}\right)$ and concentration of divalent cations $\left(\mathrm{Mg}^{2+}\right)$, biologically fully active enterobacterial endotoxins adopt, at least partially, cubic inverted structures (for a review see (5). This was found to contrast the behavior of some non-enterobacterial lipid A (from LPS of Rhodobacter capsulatus and Rhodopseudomonas viridis), for which the lack of ability to exhibit any activity was found to correlate with the preference for exclusively lamellar phases (4).

Since in the previous reports in particular for Salmonella spp. and E. coli mainly rough mutant strains were used, and in the clinical practice of infected persons mainly smooth-form LPS occur, we have extended our investigations also to the evaluation of the supramolecular structure of the latter LPS including fractions from a particular strain from Citrobacter freundii. The measurements comprise the heterogeneous, wild-type LPS from E. coli $\mathrm{O} 55: \mathrm{B} 5$, S. abortus equi, S. minnesota, and $C$. freundii. In one case, the $S$-form and R-form LPS were separated from the 
same bacterial strain (Citrobacter freundii) by gel permeation chromatography ths allowing that both LPS can be compared with respect to their bioactivity. The results clearly show a preference of the smooth-form LPS for lamellar structures below $T_{C}$ (around 35 to $40{ }^{\circ} \mathrm{C}$ ). At higher temperatures, in the X-ray diffraction patterns of several smooth form LPS also mixed lamellar/inverted structures are observed, the latter assignable to a cubic substructure.

Furthermore, in previous reports antimicrobial peptides (AMP), called synthetic anti-LPS-peptides (SALP) have been described, which showed efficient inhibition of LPS-induced cytokine release in human mononuclear cells, but also protected animals from experimental endotoxic shock $(9,10)$. In these experiments in most cases rough mutant LPS from $S$. minnesota strain R60 was taken which was assumed to represent the bioactive part of smooth LPS (11). For an extension of these findings, we have checked the ability of the SALP (lead structure Pep19-2.5) to inhibit also the cytokine induction by genuine wild-type LPS, as well as the change of its supramolecular structure, and the thermal binding by microcalorimetric titration. We have found that Pep19-2.5 binds to LPS with high affinity until saturation, changes its supramolecular aggregate structure into a multilamellar one, thereby reducing the LPS-induced tumor-necrosis-factora secretion of human MNC considerably. These observationsnow allow a general understanding of the peptide:LPS binding mechanisms.

\section{Materials and Methods}

LPS Wild-type LPS from S. minnesota, S. abortus equi, C. freundii and E. coli O55:B5 were extracted by the phenol/water technique (12) from bacteria grown at 37 ${ }^{\circ} \mathrm{C}$. LPS from Citrobacter freundii. LPS was obtained from $\mathrm{H}$. Brade, Research Center Borstel. It has been prepared by a two-step extraction procedure. First extraction by the phenol-water method (12) followed by the phenol-chloroformpetroleum ether (PCP) method (13). For isolation and separation of the smooth- and rough-form, the LPS $C$. freundii, were subjected to gel permeation chromatography (GPC) as described elsewhere (14). Before GPC of the LPS, the column was first 
calibrated with dextran-blue (Sigma, molecular weight 2.000.000 Da, Fraction 47, $211 \mathrm{~mL}$ elution volume) and cytochrome C (Sigma mol. wt. 13.000; Fraction 97, 436 elution volume). For the separation of high-.molecular weight S-form LPS from low molecular weight R-Form LPS, $150 \mathrm{mg}$ of LPS of $C$. freundii. was dispersed in $5 \mathrm{~mL}$ of $100 \mathrm{mM}$ triethylamine/acetate buffer $(\mathrm{pH} 7.2)$ at $37^{\circ} \mathrm{C}$ containing $0.5 \%(\mathrm{w} / \mathrm{v})$ desoxycholate and $0.05 \%(\mathrm{w} / \mathrm{v})$ tauryl desoxycholate prior to gel-permeatography (GPC) under ultrasonication. The whole sample applied to a $2.8 \times 97 \mathrm{~cm}$ column filled with AcA44 Ultragel (LKB, Sweden) equilibrated with the same buffer and chromatographed at $37^{\circ} \mathrm{C}$ in a jacketed column in order to avoid crystallization of the deoxycholated during chromatography. Fractions of $4.50 \mathrm{ml}$ were collected (LKB Ultrorac Fraction Collector). Aliquots of $20 \mu \mathrm{L}$ of each fraction were analyzed by the anthrone-test for neutral sugars (15) and $100 \mu \mathrm{L}$ aliquots for the analysis of Kdo serving as a chemical marker for the core oligosaccharide (16). According to the elution profile of neutral sugars and Kdo, five fractions $\left(\mathrm{F}_{1}-\mathrm{F}_{5}\right)$ differing in size were found: Fraction 1: $\leq 1 \mathrm{mg}$ (yield $<1 \%)$; fraction $2: 19.9 \mathrm{mg} \mathrm{(13.2 \% );} \mathrm{fraction} \mathrm{3:} 9.4$ $\mathrm{mg}(6.2 \%)$; fraction $4: 57.1 \mathrm{mg}(38.1 \%)$; fraction 5: 78.1 (52.0\%) $\mathrm{mg}$ (that the sum of the percentages is $>100 \%$ comes probably from the fact that not all detergent and also the buffer could not be removed completely after lyophilisation of the single pooled fractions).

These fractions were further analyzed by SDS-PAGE and compared with the parent LPS of $C$. freundii and some mutant LPS Rc to Ra from $S$. minnesota of known molecular size. SDS/PAGE was run on 16\% polyacrylamide gels (17) and silver-stained as described (18). The SDS-PAGE analysis showed for $F_{4}$ the ladderlike banding structure typical for the occurrence of the $O$ chains, which was completely absent in $\mathrm{F}_{5}$ (data not shown). The latter apparently corresponds to a rough type LPS of similar size as Rb or Rc. Details are shown in the infrared analysis in the Results section.

\section{Peptides}


The SALP structures were synthesized with an amidated C-terminus by solid-phase peptide synthesis in an automatic peptide synthesizer (model 433A; Applied Biosystems) on Fmoc-Rink amide resin, as described previously (9).

Beside Pep19-2.5, sequence GCKKYRRFRWKFKGKFWFWG (MW 2711) the variant Pep19-12, sequence GCRRFKKFKKWRYRGRFWFWCFG (MW 3145) was also used.

\section{Sample preparation}

The endotoxin samples were usually prepared as dispersions in 50 to $90 \%$ water in different Hepes and $\mathrm{Mg}^{2+}$-containing solutions $\left(\left[\mathrm{Mg}^{2+}\right]\right.$ concentrations up to $50 \mathrm{mM}$ ) at room temperature, and then cycled three times between 4 and $60{ }^{\circ} \mathrm{C}$. Prior to measurement, the samples were cooled at $4{ }^{\circ} \mathrm{C}$ at least $24 \mathrm{~h}$.

In the interaction experiments, the SALP were dissolved in Hepes buffer, heated for a short time to $60^{\circ} \mathrm{C}$ and added to the LPS at the scheduled concentrations.

\section{$X$-ray scattering}

The X-ray diffraction measurements were performed on the X33 beamline of the European Molecular Biology Laboratory (EMBL) outstation at HASYLAB on the storage ring DORIS of the Deutsches Elektronen Synchrotron (DESY) at Hamburg (19). Briefly, diffraction patterns in the range of scattering vector $0.05<\mathrm{s}<1 \mathrm{~nm}^{-1}$ (s $=2 \sin \Theta / \lambda, 2 \Theta$ is the scattering angle and $\lambda$ the wavelength $=0.15 \mathrm{~nm}$ ) were recorded with exposure times of 2 to 3 min using a linear detector (20). Further details concerning the data acquisition and evaluation have been described previously (21). In the diffraction patterns presented below, the logarithm of the diffracted intensities I(s) is plotted versus $\mathrm{s}$. The X-ray spectra were evaluated using standard procedures (22), which allow to assign the spacing ratios of the diffraction maxima to defined three-dimensional structures of the endotoxin:water samples. Structures occurring for endotoxins comprise lamellar (L) phases with spacing ratios lying at equidistant positions and non-lamellar phases like cubic $(Q)$ and inverted 
hexagonal $\left(\mathrm{H}_{\|}\right)$characterized by the occurrence of particular 'square root' spacing ratios(22),(23).

\section{FTIR spectra}

Infrared spectra were recorded on a Fourier-transform infrared spectrometer(FTIR) IFS 55 (Bruker, Karlsruhe, Germany) by using the attenuated total reflectance unit (ATR). For the measurements of the infrared spectra, the complete LPS or the different LPS fractions were dispersed in aqueous solution at a concentration of $100 \mu \mathrm{g} / 100 \mu \mathrm{l}$ on a ZnSe crystal. After slow evaporation of all free water at room temperature, the hydrated samples were measured in an attenuated total reflectance accessory as described earlier (24). The spectra were checked in the 'fingerprint' region (1200 to $900 \mathrm{~cm}^{-1}$ ) as well as in the range of the symmetric and antisymmetric stretching vibrations 2800 to $2950 \mathrm{~cm}^{-1}$ for a qualitative analysis of the amount of sugars and lipids, respectively, by comparison with LPS of defined compositions.

\section{Isothermal Titration Calorimetry (ITC)}

Microcalorimetric measurements of peptide binding to LPS were performedon a MCS isothermal titration calorimeter (Microcal, Freiburg,Germany) at $37{ }^{\circ} \mathrm{C}$ as previously described (25).LPS wild-type 055:B5 (1 mg/ml, prepared as described above) was dispensed into the microcalorimetric cell (volume:1.3 $\mathrm{ml}$ ), and the peptide solution ( $2 \mathrm{mM}$ ) was loaded into the syringe compartment (volume: $100 \mu \mathrm{l}$ ). After temperature equilibration, the peptide was titrated in $3 \mathrm{ml}$ portions every 5 min into the LPS-containing cell underconstant stirring, and the heat of interaction after each injection measured bythe isothermal titration calorimetry (ITC) instrument was plotted versus time.

\section{Stimulation of human MNC by LPS.}

Mononuclear cells (MNC) were isolated from heparinized blood samples obtained from healthy donors as described previously(9). The cells were resuspended in medium (RPMI 1640), and their number was equilibrated at $5 \cdot 10^{6}$ cells $/ \mathrm{ml}$. For stimulation, $200 \mu \mathrm{MNC}\left(1 \circ 10^{6}\right.$ cells) was transferred into each well of a 96 -well 
culture plate. LPS and the LPS/peptide mixtures were preincubated for $30 \mathrm{~min}$ at $37^{\circ} \mathrm{C}$ and added to the cultures at $20 \mu \mathrm{l}$ per well. The cultures were incubated for $4 \mathrm{~h}$ at $37^{\circ} \mathrm{C}$ with $5 \% \mathrm{CO}_{2}$. Supernatants were collected aftercentrifugation of the culture plates for $10 \mathrm{~min}$ at $400 \mathrm{~g}$ and stored at $20^{\circ} \mathrm{Cuntil}$ immunological determination of tumor necrosis factor alpha (TNF- $\alpha$ ), carried out with a sandwich enzyme-linked immunosorbent assay (ELISA) usinga monoclonal antibody against TNF (clone 6b; Intex AG, Switzerland) asdescribed previously in detail (9).

\section{RESULTS}

In the following, the aggregate structures of various wild-type LPS and fractions thereof are determined alone and in the presence of the well-described antimicrobial peptide (AMP) Pep19-2.5 by synchrotron radiation SAXS. Furthermore, biological experiments are performed by stimulating human mononuclear cells (MNC) with LPS and evaluating the cytokine induction in an ELISA (tumor-necrosisfactora): Finally, the thermodynamics of binding of Pep19-2.5 to a particular S-LPS was studied.

\section{SAXS of E. coli O55:B5}

As typical result of a small-angle $X$-ray experiment in Fig. $1 \mathrm{~A}$ the temperature dependence of the diffraction patterns is given for LPS from E. coli O55:B5 in threedimensional representation (water content $70 \%$ no $\mathrm{Mg}^{2+}$ ). The patterns exhibit characteristic changes in particular in the range of the acyl chain melting transition at 30 to $40{ }^{\circ} \mathrm{C}$. In the following, a detailed analysis of the position of individual reflections is performed in an attempt to assign the patterns to particular structures. In Fig. 1B, the results for the three temperatures 20,40 , and $60^{\circ} \mathrm{C}$ are presented. For the patterns at $20^{\circ} \mathrm{C}$, an assignment to a lamellar phase with a periodicity of $26.8 \pm 0.8 \mathrm{~nm}$ and the occurrence of the third to sixth order reflections is possible. At $40{ }^{\circ} \mathrm{C}$, the situation becomes more complex: An assignment to a lamellar phase with a periodicity at $29.1 \pm 0.8 \mathrm{~nm}$ as well as a cubic phase with a periodicity $\operatorname{atd}_{\mathrm{Q}}=16.5$ 
$\pm 0.4 \mathrm{~nm}$ and the occurrence of reflections at $d_{Q} / \sqrt{3}, d_{Q} / \sqrt{5}, d_{Q} / \sqrt{ } 8, d_{Q} / \sqrt{ } 11, d_{Q} / \sqrt{ } 16$, and $d_{Q} / \sqrt{2} 20$ is possible. Since at this temperature, however, the acyl chain melting should have taken place, one would expect a significant decrease of $d_{1}$ as compared to the value at $20{ }^{\circ} \mathrm{C}$ of $26.8 \mathrm{~nm}$. This fact and the high precision of $d_{Q}$ make the assignment to the cubic phase more probable. Similar arguments hold for the pattern at $60^{\circ} \mathrm{C}$. Here, a cubic assignment is much more probable. These data together with a list of the peak positions are presented in Table 1.

From diffraction patterns of the same LPS, but at a higher $\mathrm{Mg}^{2+}$ concentration $\left(50 \mathrm{mM} \mathrm{Mg}{ }^{2+}\right.$ ), the existence of only one lamellar structure over the entire temperature range can be deduced (data not shown). The periodicities range from $d_{1}$ $=30.0 \pm 0.5 \mathrm{~nm}$ at $20{ }^{\circ}$ Cover $d_{1}=30.5 \pm 0.4 \mathrm{~nm}$ at $40{ }^{\circ} \mathrm{C}$ to $d_{l}=33.0 \pm 0.3 \mathrm{~nm}$ at 60 ${ }^{\circ} \mathrm{C}$.

\section{SAXS of LPS from Salmonella}

The evaluation of the diffraction patterns for LPS from $S$. minnesota and $S$. abortus equibelow the phase transition temperature $T_{c}$ (around $36{ }^{\circ} \mathrm{C}$, (5)),yields only lamellar structures. Above $T_{c}$, at low or medium $\left[\mathrm{Mg}^{2+}\right](<10 \mathrm{mM})$, the analysis frequently leads to cubic (see below) or mixed lamellar/non-lamellar structures, at higher $\mathrm{Mg}^{2+}$ concentrations to pure lamellar phases (data not shown). For the latter, in Table 2 the lamellar periodicities $d_{l}$ are listed at $30^{\circ} \mathrm{C}$ clearly showing that the length of the $\mathrm{O}$ side chain may differ considerably also for Salmonella genus (compare results for $S$. abortus equi and $S$. minnesota). For a direct determination of the molecular geometries (length of the endotoxin molecules), the length of the water layer $d_{w}$ between opposite molecules must be known. Alternatively, measurements in the absence of water should eliminate $d_{w}$. However, the X-ray diffraction patterns without external added water (data not shown) indicate the existence of only unilamellar rather than multilamellar structures thus preventing a determination of the molecular geometry under water-free conditions.

SAXS patterns were recorded comparatively for LPS from $S$. abortus equi at 70 and at $90 \%$ water content (Fig. 2, top). At $90 \%$, the scattering maxima can be interpreted to result from a cubic phase with a periodicity at $d_{Q}=20.5 \pm 0.4 \mathrm{~nm}$, and further reflections at $d_{Q} / \sqrt{ } 3, d_{Q} / \sqrt{5}, d_{Q} / \sqrt{ } 8, d_{Q} / \sqrt{ } 11$, and $d_{Q} / \sqrt{ } 14$. 
As shown in Fig. 2 (bottom), at the higher water content the scattering patterns are no resolvable, only the form factor determines the scattering profile. This means that at this concentration the observed aggregate structure should be still present, but not observable due to a unfavorable signal to noise ratio.

Some measurements of the different wild-type LPS were performed at water contents 30 to $50 \%$ and showed onlydiffraction patterns typicalfor (multi)lamellar structures (not shown). .

\section{SAXS of LPS from Citrobacter freundii}

Similar X-ray diffraction patterns at a water content of $70 \%$ were recorded also for lipopolysaccharides of $C$ freundii. (data not shown). With increasing temperature, the numbers of reflections and the resolution of the maxima increased. Although assignment to only lamellar structures is possible at all temperatures, the increase of the periodicity $d_{1}$ with temperature suggests that the average number of bilayers (multilamellarity) varies considerably at the different temperature, because in pure and homogenous multibilayers $d_{1}$ must decrease due to the higher crosssection and with that, reduce the acyl chain length of the single molecules. Therefore, a detailed analysis was performed with LPS fractions as indicated in Materials and Methods. The yield of the main LPS fractions 4 and 5 was highest, allowing the application of the physical techniques in more detail.

\section{FTIR and SAXS of LPS fractions}

FTIR spectra of the different LPS fractions were recorded. The comparison of all fractions show that only fractions 4 and 5 correspond to relatively pure LPS, while the other fractions contain considerable amounts of proteins as can be deduced from the strong amide bands at 1650 and $1550 \mathrm{~cm}^{-1}$ (data not shown), see (26). An infrared spectrum of the two fractions as compared to a rough mutant $\mathrm{Ra}$ from Salmonella minnesota R60 is plotted in Fig. 3. In the figure, the different spectral ranges are presented. Important is in particular the ratio of the strong lipid bands 
(symmetric and antisymmetric stretching vibrations of the methylene groups at 2850 and $2920 \mathrm{~cm}^{-1}$, respectively) and the sugar bands in the range 1000 to $1200 \mathrm{~cm}^{-1}$. The spectra of the two fractions 4 and 5 are characteristic for an LPS with and without O-antigen, respectively (26). Furthermore, fraction 4 has a smaller content of fatty acid residues (weaker peak intensity corresponding to the lipid A portion). The comparison with a defined LPS structure from $S$. minnesota strain R60 shows that fraction 5 is nearly identical with the latter, indicating that this sample corresponds to an Ra form LPS.

X-ray scattering patterns are given in Figs. $4 \mathrm{~A}-\mathrm{B}$ for fractions 4 and 5 each at 20 and $40{ }^{\circ} \mathrm{C}$. The reflections of fraction 4 at $40{ }^{\circ} \mathrm{C}, 9.26,7.04,5.65,4.65$, and 3.97 $\mathrm{nm}$ can be assigned to a cubic inverted structure with a periodicity at $d_{Q}=16.0 \pm 0.2$ $n m$, since the relations $d_{Q} / \sqrt{3}, d_{Q} / \sqrt{5}, d_{Q} / \sqrt{ } 8, d_{Q} / \sqrt{12}$, and $d_{Q} / \sqrt{ } 16$ hold true. The scattering patterns of fraction 5 also allow the assignment to a cubic structure, since the peaks at $8.58,5.72$, and $4.44 \mathrm{~nm}\left(\right.$ at $40{ }^{\circ} \mathrm{C}$ ) hold the relations $\mathrm{d}_{\mathrm{Q}} / \sqrt{5}, \mathrm{~d}_{\mathrm{Q}} / \sqrt{ } 11$, and $d_{Q} / 118$, with $d_{Q}=18.9 \pm 0.3 \mathrm{~nm}$. An assignment to a cubic phase of a particular space group is not possible, although space groups $Q^{212}$ and $Q^{224}$ may play a role as previously found for lipid A (27).

\section{SAXS of LPS in the presence of Pep19-2.5}

SAXS measurements were also performed for LPS from $S$. abortus equi in the presence of the peptide at a concentration $1: 1$ weight $\%$ and at $90 \%$ water content to realize near physiological conditions (Fig. 5). The comparison with Fig. 3 exhibits a clear change of the scattering pattern. There is only one sharp scattering maximum around 8.80 to $9.20 \mathrm{~nm}$. This can be assigned to a multilamellar structure with the expression of only the first order periodicity.

\section{LPS-induced cytokine induction.}

For the stimulation experiments, LPS from $S$. abortus equi, LPS from $C$. freundii, and their LPS fractions $4\left(F_{4}\right)$ and $5\left(F_{5}\right)$ were taken. In figure 6 the results are shown for LPS fraction 4 alone and in the presence of Pep19-2.5 and another SALP Pep19-12. Clearly, the presence of the peptide considerably deceases the cytokine-inducing 
activity of the LPS, with a slightly higher inhibition of Pep19-2.5 as compared to Pep19-12 in accordance to previous findings on rough mutant LPS $(9,10)$. LPS from C. freundii gave already significant inhibition at a peptide concentration $1: 1$ weight\% (data not shown). The results for the two LPS fractions from $C$. freundii exhibit also a high stimulation efficiency (note that the absolute values of cytokine secretion cannot be compared due to different blood donors), and a similar inhibition of the cytokine secretion in the presence of Pep19-2.5 (Fig. 7).

\section{LPS binding to Pep19-2.5}

Isothermal titration calorimetry was applied to measure the enthalpy change of the binding of S-form LPS O55:B5 to Pep19-2.5. As shown in Fig. 8, in which the results of four independent experiments are summarized, the binding of the peptide is a strong exothermic reaction starting with nearly $80 \mathrm{~kJ} / \mathrm{mole}$, and having an S-shaped form characteristic for complex formation and binding saturation. The interaction of the LPS is governed by Coulomb forces between the positive charges of the peptide and the negative charges of LPS, and in a second step a further hydrophobic interaction of the respective parts. If a molecular weight of 10000 for LPS is assumed, then the saturation value of $[\mathrm{Pep}]:[\mathrm{LPS}]=0.25$ weight ratio would mean, that the 8 positive charges of the peptide are completely neutralized at a molar ratio of $1: 1$.

\section{DISCUSSION}

The results from the investigations of the aggregate structures of wild-type LPS presented here exhibit a complex structural polymorphism similar to that found for their rough mutant counterparts $(6,22,28)$. The main difference, however, is the fact that all wild-type LPS consist of a variety of different subfractions, which are up to now not characterized in detail for most LPS. Since the pioneering work of the group of Galanos et al. (11) it turned out, that within the heterogeneous LPS a rough mutant LPS with lacking O-antigen seems to be the bioactive unit, and that the complexity of wild-type LPS apparently is governed by its functional role in the outer 
membrane.

Overall, the data presented in Figs. 1-3 and Tables1-2 clearly show a dependence of the aggregate structure on phase state (temperature), water content, and cation concentration. Thus, comparing the results with previous reports from rough mutant LPS, a general picture of the structural preferences of enterobacterial endotoxins can now be drawn: At high water content under near physiological conditions, the predominant supramolecular structure is cubic or mixed lamellar/cubic for all endotoxins. Furthermore, only endotoxins with short sugar chains (lipid A, LPS Re) may adopt the inverted hexagonal structure $H_{\|}$at elevated temperatures. At a water content $<50 \%$, which represents the approximate boundary between free and completely bound water, only lamellar structures are assumed for all compounds at least below $50{ }^{\circ} \mathrm{C}$. In the presence of $\mathrm{Mg}^{2+}$, the nonlamellar cubic structures convert completely to multilamellar structures at [endotoxi$\mathrm{n}]:\left[\mathrm{Mg}^{2+}\right] \leq 1 \mathrm{M}$, again for all endotoxins.

From these results, one might be tempted to connect the tendency of endotoxins for non-lamellar structures under physiological conditions of temperature, water content, and concentrations of divalent cations with the expression of biological activity. A strong confirmation of such a connection was found previously(4) for various lipid A preparations of different origin, in which the samples assuming inverted (cubic, $H_{\|}$) structures have highest, those with mixed lamellar/non-lamellar have a significantly lower activity, and those adopting only lamellar structures are nearly completely inactive $(4,7)$.

Regarding literature data, most ultrastructural investigations were performed with rough mutant LPS. For wild-type LPS, some data of the LPS morphology were published, by using negative staining microscopy, dynamic light scattering spectroscopy, and dynamic atomic force microscopy ((29), (30) (31), from which a variety of LPS morphologies such as ribbon-like structures, hetreogenous spherical particles, lipidic particles and others were found. In none of these investigations, however, techniques like SAXS ans SANS were performed which allowed beyond the morphology the determination of the three-dimensional aggregate structure. An overview of these findings is given by Richter et al. (32).

The data for the fractions 4 and 5 from $C$. freundii showed both high immune 
stimulation indicating that the length of the sugar chain - fraction 4 expresses the whole O-antigen - does not play a role for the biological activity of the LPS, but apparently may play be important for the defense of the bacteria against external agents (33). Unfortunately, the exact chemical structure of the lipid A moieties of the two LPS fractions was not be analyzed in detail, it seems only that fraction 4 may be slightly underacylated as compared to complete hexaacyl lipid A. Such change of the acyl chain moiety, however, would not be observable in the bioactivity test, because in this even an only $50 \%$ hexaacylated lipid A with significant presence of pentaand tetraacylated species can nearly not be differentiated from a $100 \%$ hexaacylated form (34). More important, however, is the finding (Figs. 7) that the effect of the peptide in each case leads to an inhibition of the cytokine secretion, again showing that the sugar moiety does not play a role in this process. This is in accordance with the observation that Pep19-2.5 neutralizes LPS from a variety of different sources $((10,35)$, and unpublished data).

A similar finding of the inhibition of the bioactivity was found for the LPS from $S$. abortus equi and the peptide (Fig. 6). In this case, the data of the SAXS experiments are of high interest (Figs. 2 and 4). In the absence of the peptide (Fig. 2) the data are indicative of a complex, mixed lamellar/non-lamellar, SAXS pattern, whereas in the presence of the peptide (Fig. 5) a multilamellar structure is found with a periodicity of 8.8 to $9.2 \mathrm{~nm}$. It is interesting to note that this periodicity corresponds to that of LPS Ra under conditions, in which this LPS forms multilamellar aggregates (low water content and/or high $\mathrm{Mg}^{2+}$ concentration) as found previously (28). Thus, the observed inactivation of this LPS can be interpreted as a binding of the peptide to the bioactive LPS within the heterogeneous S-LPS, corresponding to a rough type Ra as proposed by Jiao and Galanos (11). These authors (36) and Jiao et al(11) separated the smooth form LPS from Salmonella abortus equi into three distinct fractions, a long-chain fraction with an O-chain containing 20 to 50 repeating units, a short-chain fraction consisting of a rough-type LPS and another with 1 to 6 repeating units, and an $R$ fraction identical to the LPS synthesized by $R a / R b$ mutants. Interestingly, in the lipid A part the amount of fatty acid residues of the long chain fraction was drastically reduced (only $60 \%$ ) as compared to that of the $\mathrm{R}$ fraction.

The neutralization of LPS by binding to the SALP as found here and in various 
recent reports $(9,10,25)$ is directly correlated to a high affinity binding of the peptide to the LPS assembly as evidenced previously for Ra-LPS exhibiting a binding constant of $2.4 \cdot 10^{8} / \mathrm{mole}$ (25) and here for S-form LPS (Fig. 8). As indicated in the figure, the binding has high affinity with saturation characteristics, and looks very similar to what has been found for R-LPS, but the unknown molecular weight of this LPS does not allow to determine a binding constant.

The comparison of the results of the inhibition of the LPS-induced cytokine secretion for the two peptides Pep19-2.5 and Pep19-12 (Fig. 6) shows the general ability of the peptides from the SALP series to reduce the inflammation reaction, as previously found also in the mouse model of endotoxemia (10). The data in Fig. 6 and further unpublished results are, however, indicative, that slight changes in the amino acid sequence of the peptides modify the biological reaction, from which the optimal candidate Pep19-2.5, called Aspidasept ${ }^{\circledR}$ was found in a longer selection and optimization process. The latter compound fits perfectly to the lipid A part of LPS, leading to its neutralization in a kind of sequestration process.

\section{Acknowledgements}

The authors are grateful to Sabrina Groth for performing the stimulation experiments of TNFa, and the German ministry BMBF for financial help in the frame of a preclinical study "Therapy of infectious diseases with special regards to bacterial sepsis (project: 01GU0824).

\section{Literature}

1. Rietschel ET, Brade H. Bacterial endotoxins. Sci Am. 1992;267:54-61.

2. Rietschel ET, Brade L, Lindner B, Z,hringer U. Biochemistry of lipopolysaccharides. In: Morrison DC, Ryan JL, editors. Bacterial Endotoxic Lipopolysaccharides, Vol I: Molecular Biochemistry and Cellular Biology. 1. Boca Raton: CRC Press; 1992. p. 3-41.

3. Rietschel ET, Brade L, Lindner B, Z, hringer U. Molecular biochemistry of lipopolysaccharides; overview and future directions. In: Morrison DC, Ryan JL, editors. Bacterial endotoxic lipopolysaccharides, Vol 1. Boca Raton: CRC Press; 1992. p. (in press). 
4. Brandenburg K, Mayer H, Koch MHJ, Weckesser J, Rietschel ET, Seydel U. Influence of the supramolecular structure of free lipid A on its biological activity. European Journal of Biochemistry. 1993;218:555-63.

5. Brandenburg K, Andra J, Muller M, Koch MH, Garidel P. Physicochemical properties of bacterial glycopolymers in relation to bioactivity. Carbohydrate research. 2003;338(23):2477-89.

6. Brandenburg K, Koch MHJ, Seydel U. Phase diagramm of deep rough mutant lipopolysaccharide from Salmonella minnesota R595. JStructBiol. 1992;108:93-106.

7. Brandenburg K, Wiese A. Endotoxins: relationships between structure, function, and activity. CurrTopMedChem. 2004;4(11):1127-46.

8. Brandenburg K, Seydel U. Investigation into the fluidity of lipopolysaccharide and free lipid A membrane systems by Fourier-transform infrared spectroscopy and differential scanninig calorimetry. European Journal of Biochemistry. 1990;191:22936.

9. Gutsmann T, Razquin-Olazaran I, Kowalski I, Kaconis Y, Howe J, Bartels R, et al. New antiseptic peptides to protect against endotoxin-mediated shock. Antimicrob Agents Chemother. 2010;54(9):3817-24.

10. Heinbockel L, Sanchez-Gomez S, Martinez de Tejada G, Domming S, Brandenburg J, Kaconis $Y$, et al. Preclinical investigations reveal the broad-spectrum neutralizing activity of peptide Pep19-2.5 on bacterial pathogenicity factors. Antimicrob Agents Chemother. 2013;57(3):1480-7.

11. Jiao B, Freudenberg M, Galanos C. Characterization of the lipid A component of genuine smooth-form lipopolysaccharide. European Journal of Biochemistry. 1989;180:515-8.

12. Westphal O. J, K. Bacterial lipopolysaccharides. Extraction with phenol:water and further application of the procedure. Methods Carbohydrate Chemistry. 1965;5:83-91.

13. Galanos C, L - deritz O, Westphal O. A new method for the extraction of $R$ lipopolysaccharides. European Journal of Biochemistry. 1969;9:245-9.

14. Vukajlovich SW, Morrison DC. Conversion of lipopolysaccharides to molecular aggregates with reduced subunit heterogeneity: demonstration of LPSresponsiveness in "endotoxin-unresponsive" $\mathrm{C} 3 \mathrm{H} / \mathrm{HeJ}$ splenocytes. $\mathrm{J}$ Immunol. 1983;130(6):2804-8.

15. Trevelyan WE, Forrest RS, Harrison JS. Determination of yeast carbohydrates with the anthrone reagent. Nature. 1952;170(4328):626-7.

16. Brade H, Galanos C, L- deritz O. Differential determination of the 3-deoxy-Dmannooctulosonic acid in lipopolysaccharides of Salmonella minnesota rough mutants. European Journal of Biochemistry. 1983;131:195-200.

17. Laemmli UK. Cleavage of structural proteins during the assembly of the head of bacteriophage T4. Nature. 1970;227(5259):680-5.

18. Tsai CM, Frasch CE. A sensitive silver stain for detecting lipopolysaccharides in polyacrylamide gels. Anal Biochem. 1982;119(1):115-9.

19. Koch MHJ, Bordas J. X-ray diffraction and scattering on disordered systems using synchrotron radiation. NucllnstrMeth. 1983;208:461-9.

20. Gabriel A. Position-sensitive X-ray detector. RevScilnstrum. 1977;48:1303-5.

21. Boulin C, Kempf R, Koch MHJ, McLaughlin SM. Data appraisal,evaluation and display for synchrotron radiation experiments:Hardware and software. NucllnstrMeth. 1986;A249:399-407. 
22. Brandenburg K, Koch MHJ, Seydel U. Phase diagram of lipid A from Salmonella minnesota and Escherichia coli rough mutant lipopolysaccharide. JStructBiol. 1990;105:11-21.

23. Luzzati V, Gulik A, Gulik-Krzywicki T, Tardieu A. Lipid polymorphism revisited: Structural aspects and biological implications. Lipids and Membranes: Past, Present, and Future. Amsterdam: Elsevier; 1986. p. 137-51.

24. Brandenburg K, Seydel U. Fourier transform infrared spectroscopy of cell surface polysaccharides. In: Mantsch $\mathrm{HH}$, Chapman D, editors. Infrared Spectroscopy of Biomolecules. New York: Wiley Liss; 1996. p. 203-37.

25. Kaconis Y, Kowalski I, Howe J, Brauser A, Richter W, Razquin-Olazaran I, et al. Biophysical mechanisms of endotoxin neutralization by cationic amphiphilic peptides. Biophys J. 2011;100(11):2652-61.

26. Brandenburg K, Seydel U. Infrared spectroscopy of glycolipids. Chemistry and Physics of Lipids. 1998;96:23-40.

27. Brandenburg K, Richter W, Koch MHJ, Meyer HW, Seydel U. Characterization of the nonlamellar cubic and $\mathrm{H}$ II structures of lipid A from Salmonella enterica serovar Minnesota by X-ray diffraction and freeze-fracture electron microscopy. Chemistry and Physics of Lipids. 1998;91:53-69.

28. Seydel U, Koch MHJ, Brandenburg K. Structural polymorphisms of rough mutant lipopolysaccharides $\mathrm{Rd}$ to $\mathrm{Ra}$ from Salmonella minnesota JStructBiol. 1993;110:232-43.

29. Bergstrand A, Svanberg C, Langton M, Nyden M. Aggregation behavior and size of lipopolysaccharide from Escherichia coli O55:B5. Colloids SurfB Biointerfaces. 2006;53(1):9-14.

30. Santos NC, Silva AC, Castanho MA, Martins-Silva J, Saldanha C. Evaluation of lipopolysaccharide aggregation by light scattering spectroscopy. Chembiochem. 2003;4(1):96-100.

31. Aurell CA, Hawley ME, Wistrom AO. Direct visualization of gram-negative bacterial lipopolysaccharide self-assembly. MolCell BiolResCommun. 1999;2(1):426.

32. Richter W, Vogel V, Howe J, Steiniger F, Brauser A, Koch MH, et al. Morphology, size distribution, and aggregate structure of lipopolysaccharide and lipid A dispersions from enterobacterial origin. Innate immunity. 2011;17(5):427-38.

33. Nikaido $\mathrm{H}$. Molecular basis of bacterial outer membrane permeability revisited. MicrobiolMolBiolRev. 2003;67(4):593-656.

34. Mueller M, Lindner B, Kusumoto S, Fukase K, Schromm AB, Seydel U. Aggregates are the biologically active units of endotoxin. Journal of Biological Chemistry. 2004;279(25):26307-13.

35. Martinez de Tejada G, Sanchez-Gomez S, Razquin-Olazaran I, Kowalski I, Kaconis $\mathrm{Y}$, Heinbockel $\mathrm{L}$, et al. Bacterial cell wall compounds as promising targets of antimicrobial agents I. Antimicrobial peptides and lipopolyamines. Current drug targets. 2012;13(9):1121-30.

36. Galanos C, Jiao B, Komuro T, Freudenberg MA, L• deritz O. Large-scale fractionation of S-form lipopolysaccharide from Salmonella abortus equi . Chemical and serological characterization of the fractions. JChromatogr. 1988;440:397-404. 


\section{Figure legends}

\section{Figure 1A}

SAXS of LPS S-form 055:B5 from Escherichia coli at $70 \%$ water content in dependence on temperature. The logarithm of the scattering intensity is plotted versus the scattering vector $s=1 / d$ ( $d$ spacings of the reflections).

The peak positions of the single scattering maxima and the assignment to particular aggregate structures are presented in Table 1.

\section{Figure 1B}

SAXS of LPS S-form 055:B5 from Escherichia coli at $70 \%$ water content at 20,40, and $60{ }^{\circ} \mathrm{C}$. The logarithm of the scattering intensity is plotted versus the scattering vector $s=1 / d$ ( $d$ spacings of the reflections).

The scattering maxima can be assigned to lamellar and cubic structures, see text and Table 1.

\section{Figure 2}

SAXS of LPS S-form from Salmonella abortus equi at $40{ }^{\circ} \mathrm{C}$ and the two water contents $70 \%$ (top) and $90 \%$ (bottom). The logarithm of the scattering intensity is plotted versus the scattering vector $s=1 / d$ ( $d$ spacings of the reflections). The scattering pattern at $70 \%$ water content can be assigned to a cubic phase.

\section{Figure 3}

Infrared spectrum of LPS from Salmonella minnesota Ra mutant strain R60, and LPS fractions 4 and 5 from Citrobacter freundii wild type. The single peaks are assigned to particular vibrational bands as indicated.

Figure 4A 
SAXS of LPS S-form from Citrobacter freundii fraction 4 at 20 and $40{ }^{\circ} \mathrm{C}$. The logarithm of the scattering intensity is plotted versus the scattering vector $s=1 / d(d$ spacings of the reflections).

\section{Figure 4B}

LPS S-form from Citrobacter freundii fraction 5 at 20 and $40{ }^{\circ} \mathrm{C}$. The logarithm of the scattering intensity is plotted versus the scattering vector $s=1 / d$ ( $d$ spacings of the reflections).

\section{Figure 5}

SAXS of LPS S-form from Salmonella abortus equi in the presence of a 1:1 weight \% peptide Pep19-2.5, at $20-80^{\circ} \mathrm{C}$. The logarithm of the scattering intensity is plotted versus the scattering vector $s=1 / d$ ( $d$ spacings of the reflections).

\section{Figure 6}

Induction of tumor-necrosis-factora in human mononuclear cells by LPS from Salmonella abortus equi in the absence (left) and presence (medium and right) of the peptides Pep19-2.5 and Pep19-12 at [LPS]:[Pep] 1:10 weight \%. .

\section{Figure 7}

Induction of tumor-necrosis-factora in human mononuclear cells by LPS from Citrobacter freundii fractions 4 and 5 in the absence and presence of Pep19-2.5 at [LPS]:[Pep] 1:10 weight \%.

\section{Figure 8:}

Isothermal titration calorimetric data of the interaction of LPS from E. coli O55:B5 with peptide Pep19-2.5. For this, the peptide $(2 \mathrm{mM})$ was titrated in $3 \mu$ portions every $5 \mathrm{~min}$ into the LPS $(1 \mathrm{mg} / \mathrm{ml})$-containing cell, and the resulting calorimetric exotherm was recorded. 


\begin{tabular}{|c|c|c|}
\hline $\begin{array}{l}\text { Temperature } \\
\left({ }^{\circ} \mathrm{C}\right)\end{array}$ & Peak positions $(\mathrm{nm})$ and proposed assignment(s) & $\begin{array}{l}\text { Aggregate } \\
\text { Structure(s) }\end{array}$ \\
\hline 30 & $\begin{array}{llll}9.09 & 6.94 & 5.56 & 4.56 ; d_{l}=27.6 \pm 0.2 \mathrm{~nm} \text { and } \\
d_{l} / 3 & d_{l} / 4 \quad d_{/} / 5 & d_{/} / 6\end{array}$ & Lamellar \\
\hline 35 & $\begin{array}{llll}9.26 & 7.14 & 5.68 & 4.66 ; d_{l}=28.2 \pm 0.4 \mathrm{~nm} \text { and } \\
d_{1} / 3 & d_{1} / 4 & d_{/} / 5 & d_{/} / 6\end{array}$ & Lamellar \\
\hline 40 & $\begin{array}{l}9.437 .245 .874 .924 .233 .64 \\
\text { Assignment } 1: \quad d_{1}=29.1 \pm 0.8 \mathrm{~nm} \text { and } \\
\text { reflections at } d_{/} / 3 \text { to } d_{1} / 8 ; \\
\text { Assignment } 2: \\
\text { reflections at } d_{Q} / \sqrt{ } 3, d_{Q} / \sqrt{5}, d_{Q} / \sqrt{ } 8, d_{Q} / \sqrt{ } 11, d_{Q} / \sqrt{ } 16 \text {, } \\
d_{Q} / \sqrt{2} 20\end{array}$ & $\begin{array}{l}\text { Mixed } \\
\text { Lameller } \\
\text { Cubic }\end{array}$ \\
\hline 60 & 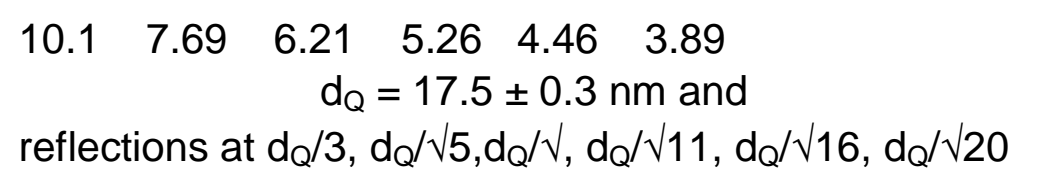 & Cubic \\
\hline
\end{tabular}

Table 1: Peak maxima of the reflections shown in Fig. 1for LPS from E. coli O55:B5 at some selected temperatures and their assignment to supramolecular structures

\begin{tabular}{||l|l||}
\hline $\begin{array}{l}\text { LPS sample from } \\
\text { (at } 30^{\circ} \mathrm{C} \text { and } 70 \% \text { water content) }\end{array}$ & $\mathbf{d}_{\mathbf{l}}(\mathbf{n m})$ \\
\hline E. coli O55:B5 & $27.6 \pm 0.3$ \\
\hline S. minnesota & $36.5 \pm 0.3$ \\
\hline S. abortus equi & $24.0 \pm 0.4$ \\
\hline C. freundii & $28.5 \pm 0.3$ \\
\hline
\end{tabular}

Table 2: Periodicities $d_{l}$ of the lamellar structures of different S-form LPS at $70 \%$ water content and $30{ }^{\circ} \mathrm{C}$ found in the presence of $\geq 50 \mathrm{mM} \mathrm{Mg}^{2+}$ 
Figures

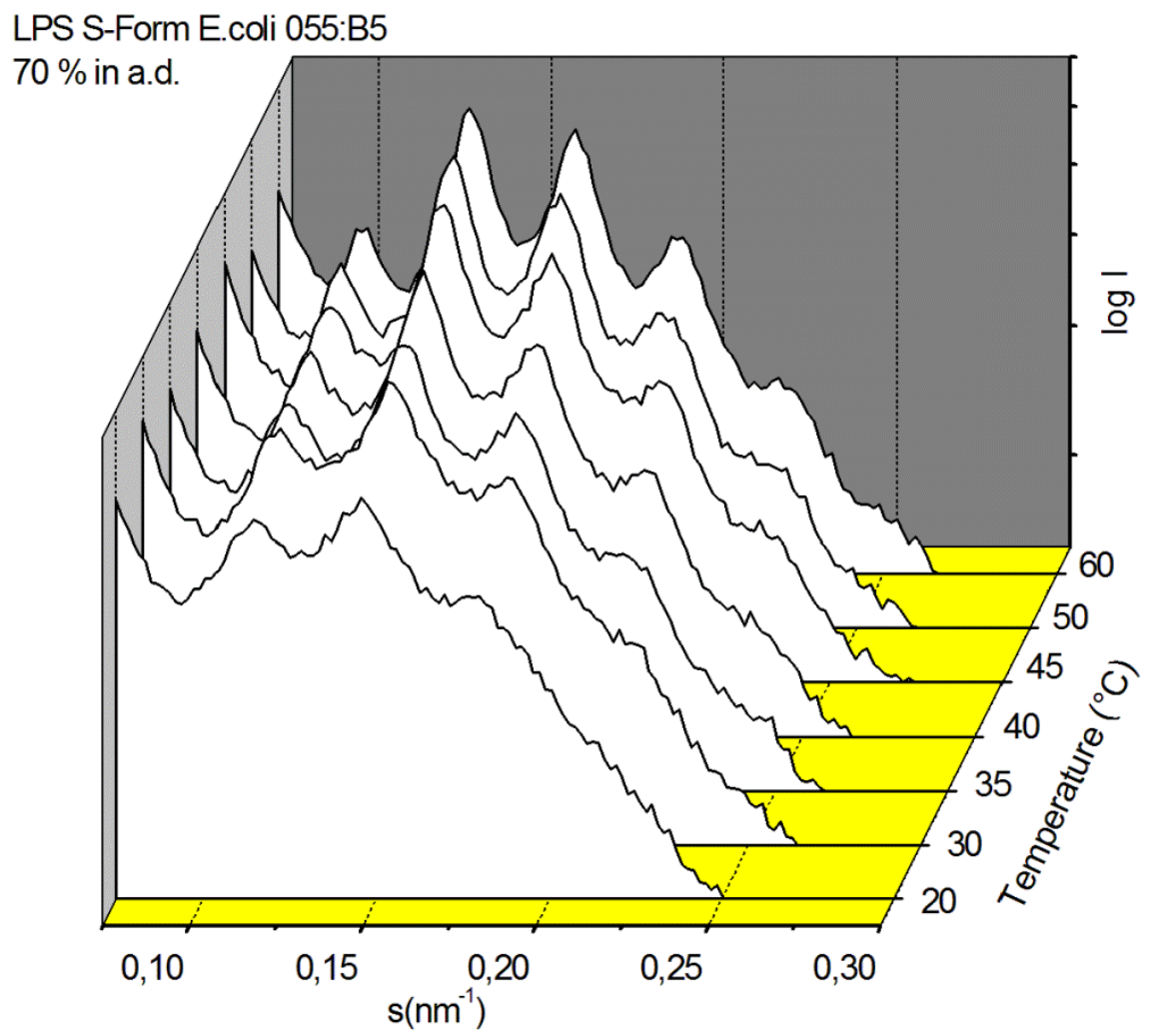

Figure 1A 


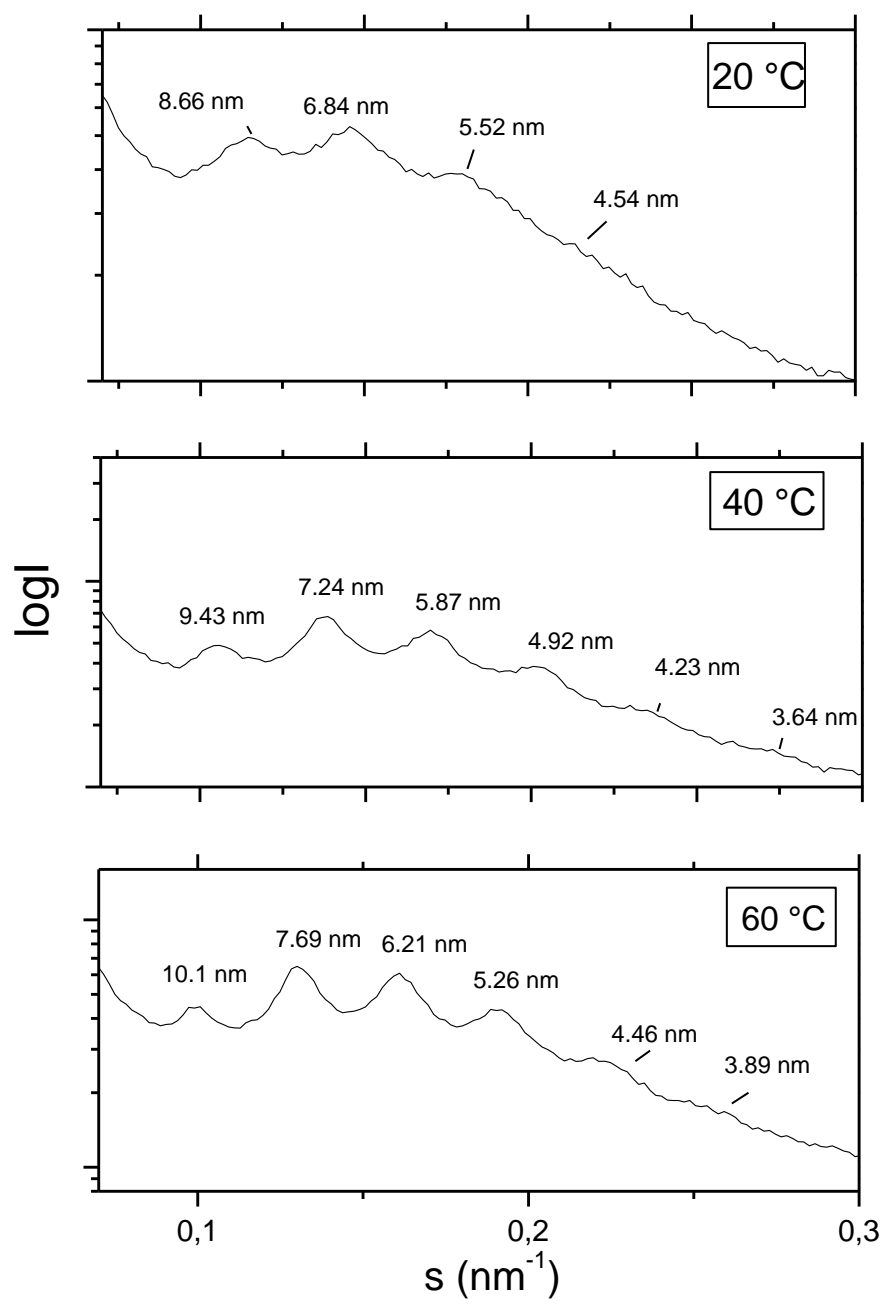

Figure 1B 


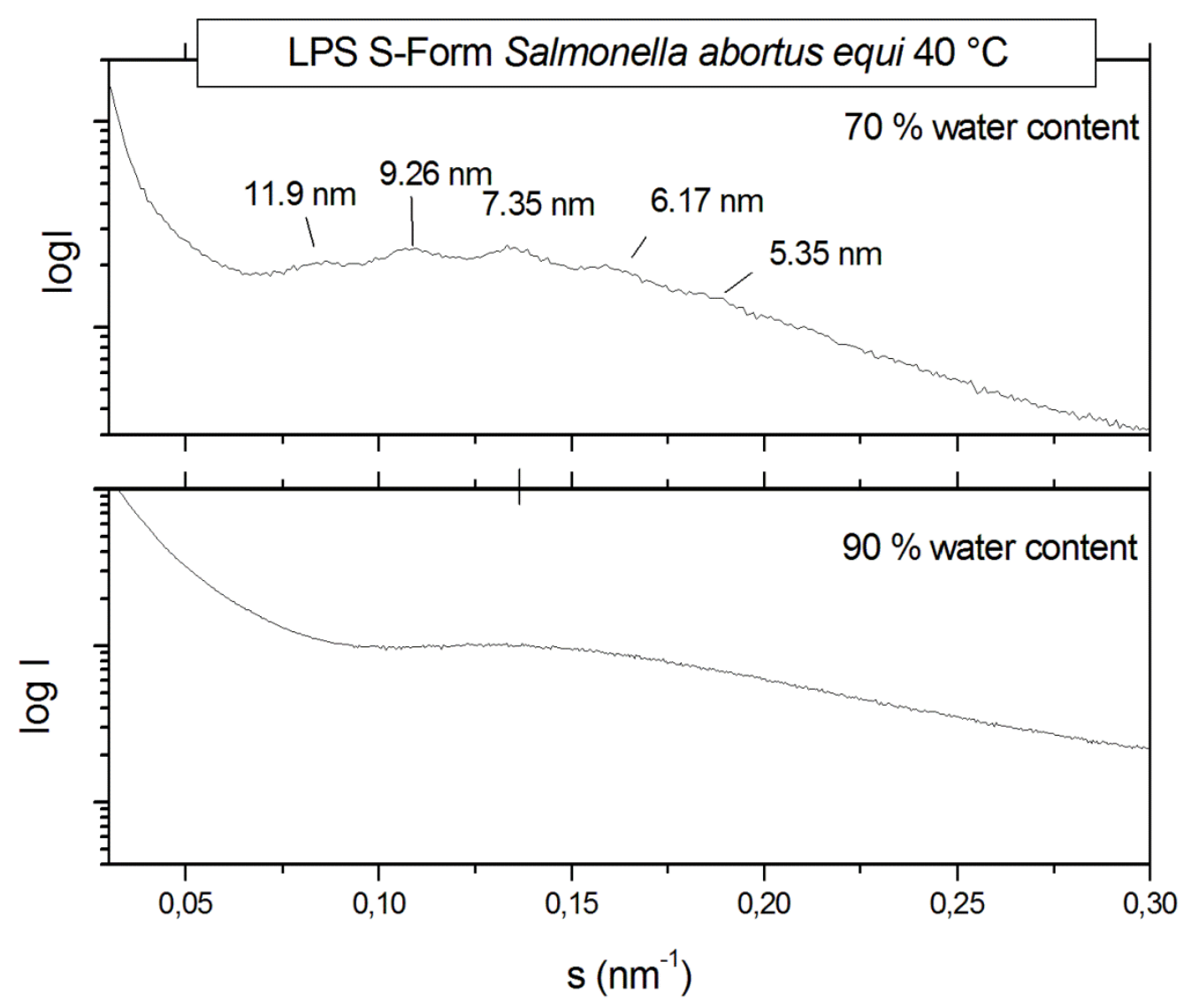

Figure 2 


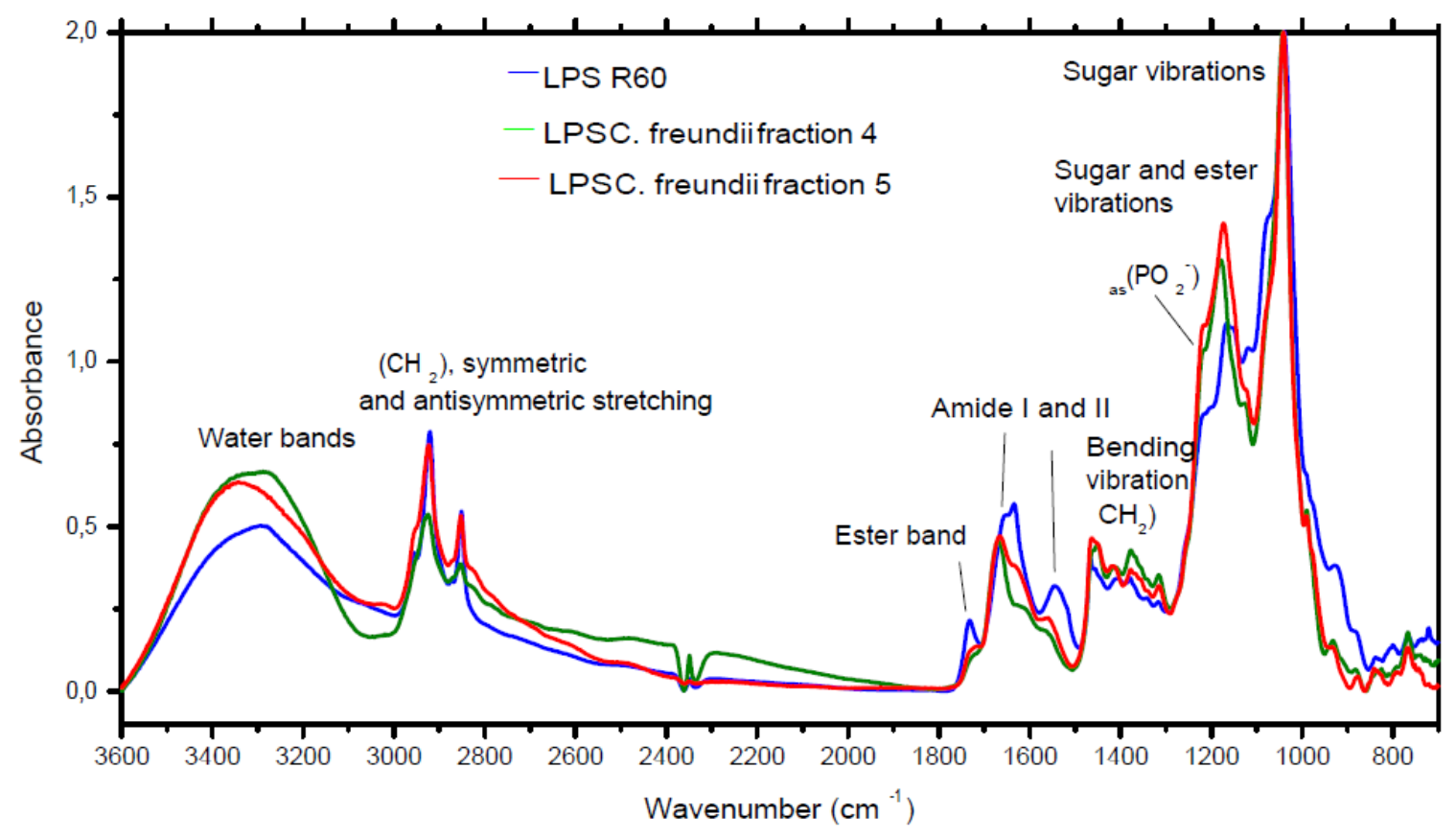

Figure 3 

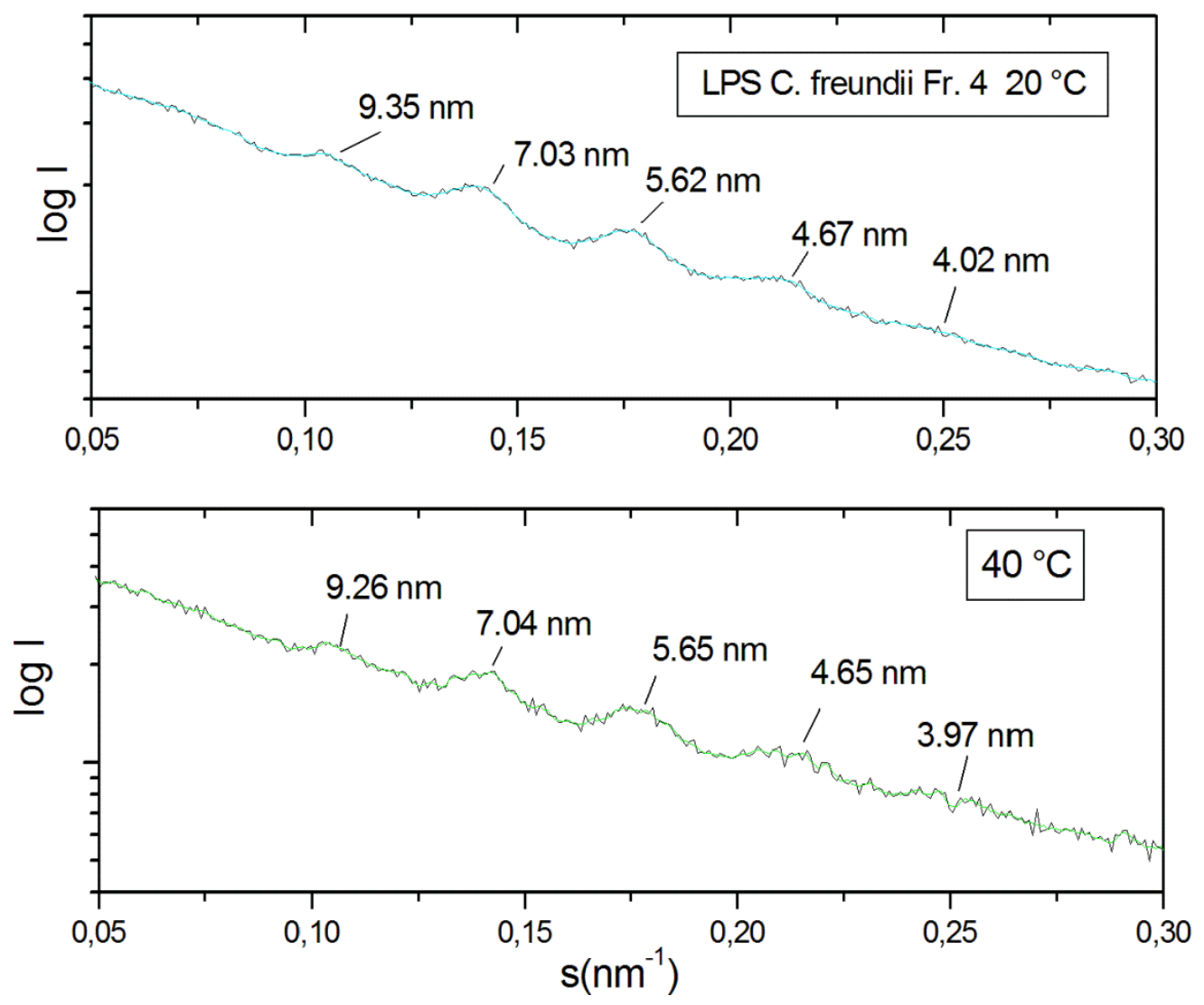

Figure 4A 

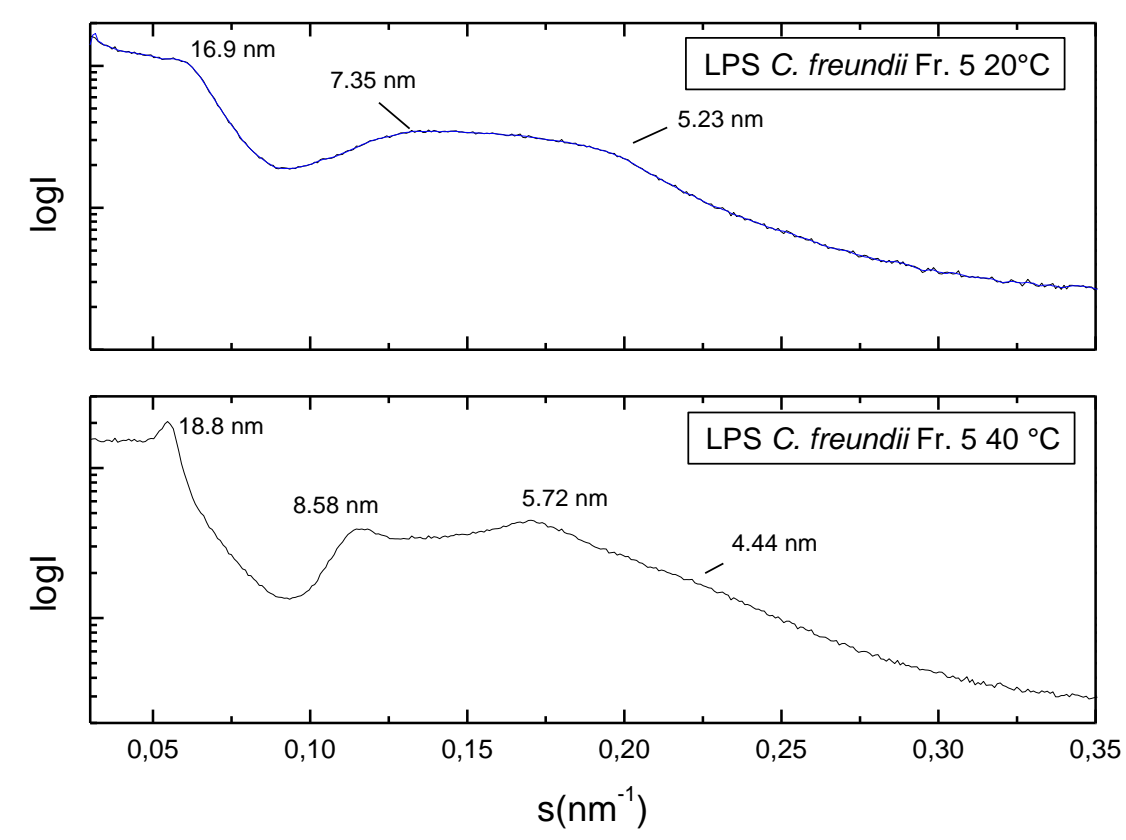

Figure 4B 


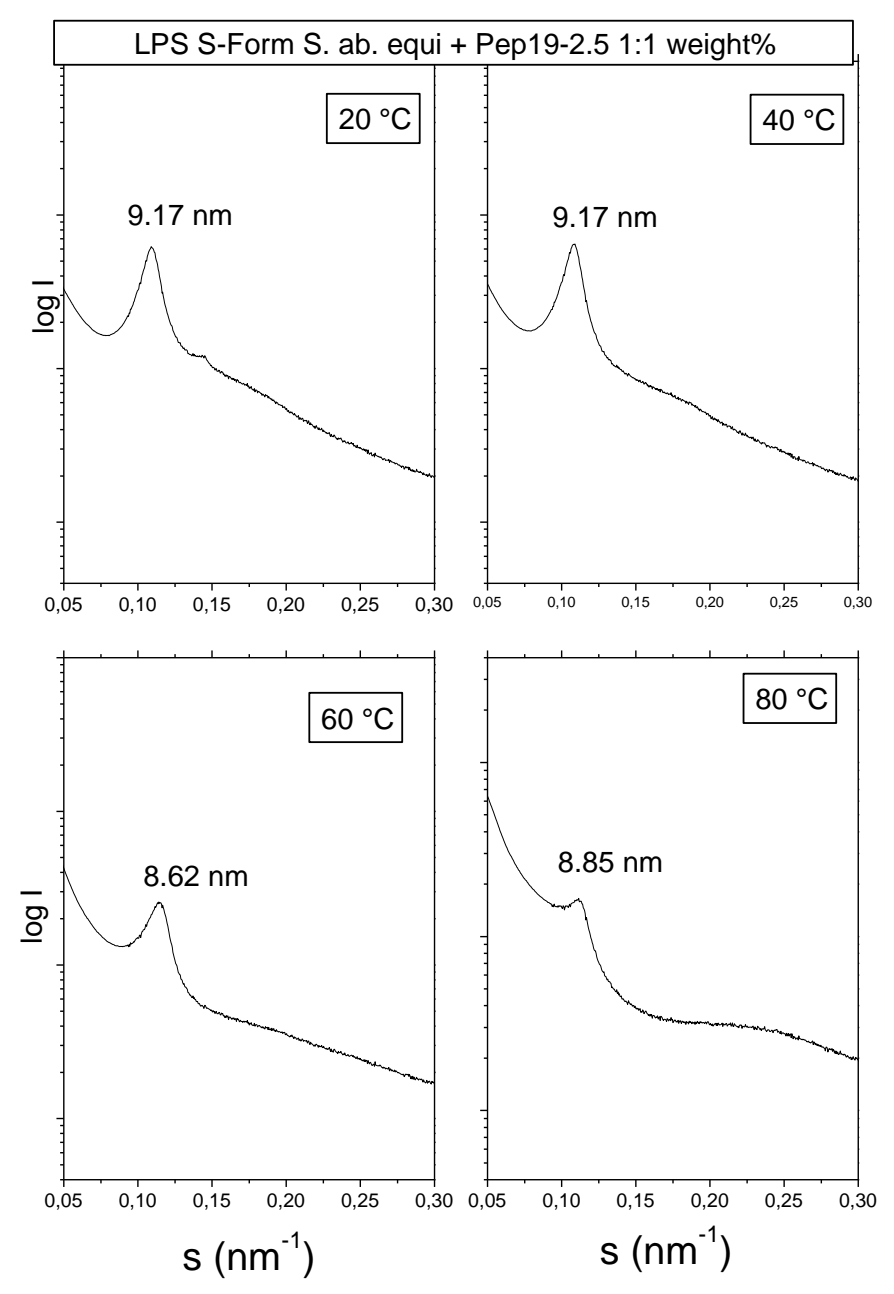

Figure 5 


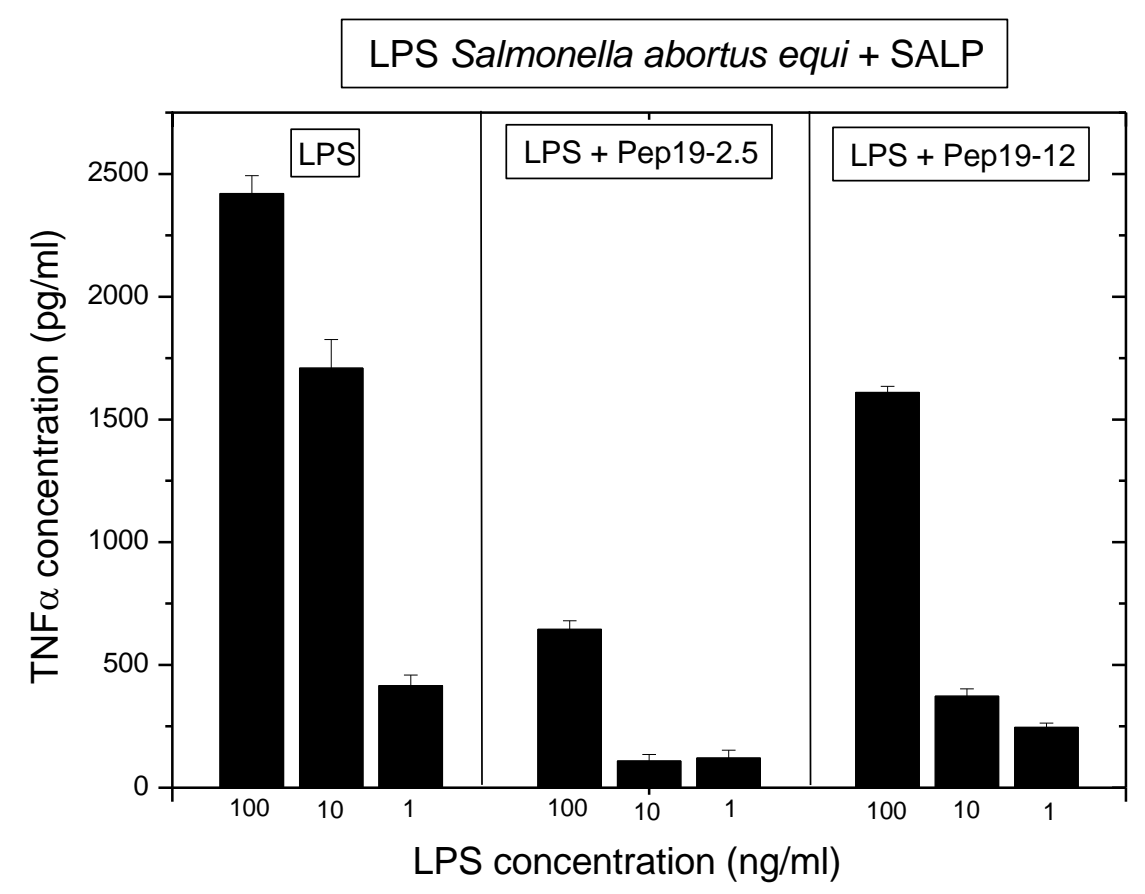

Figure 6 


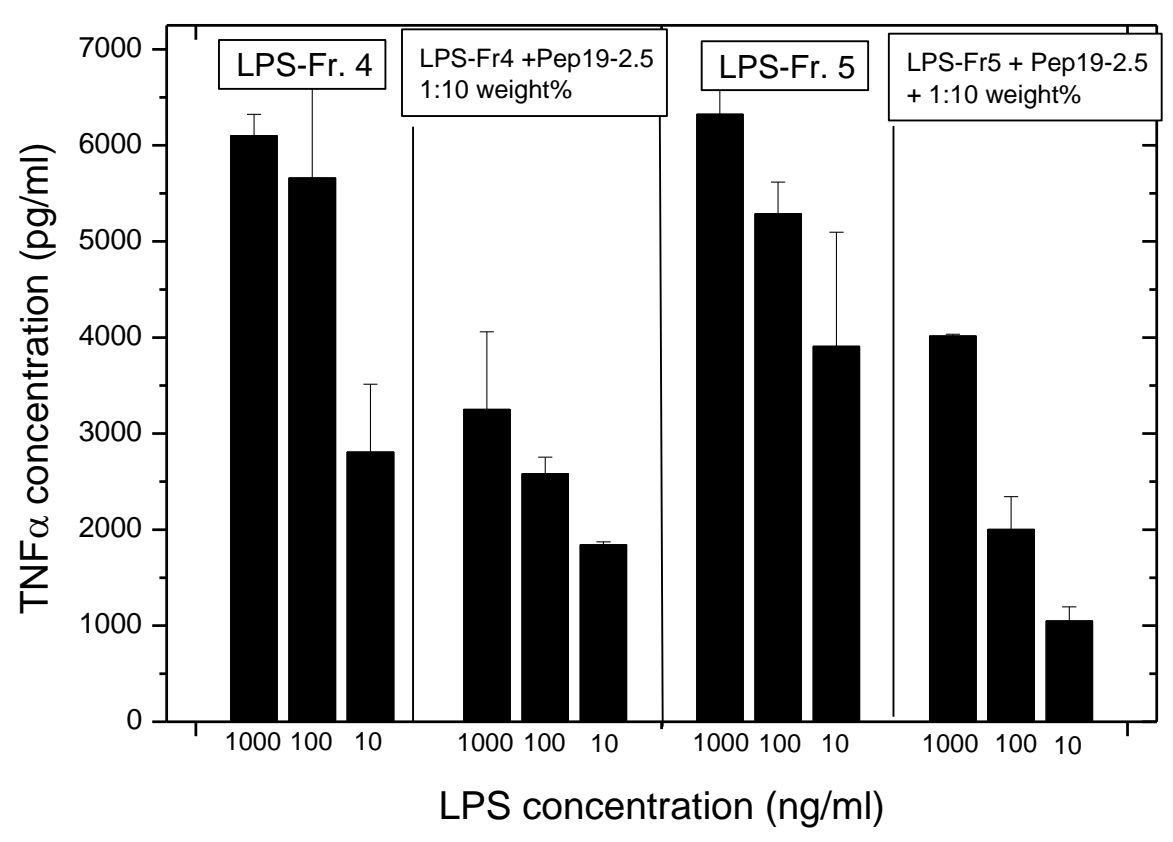

Figure 7 


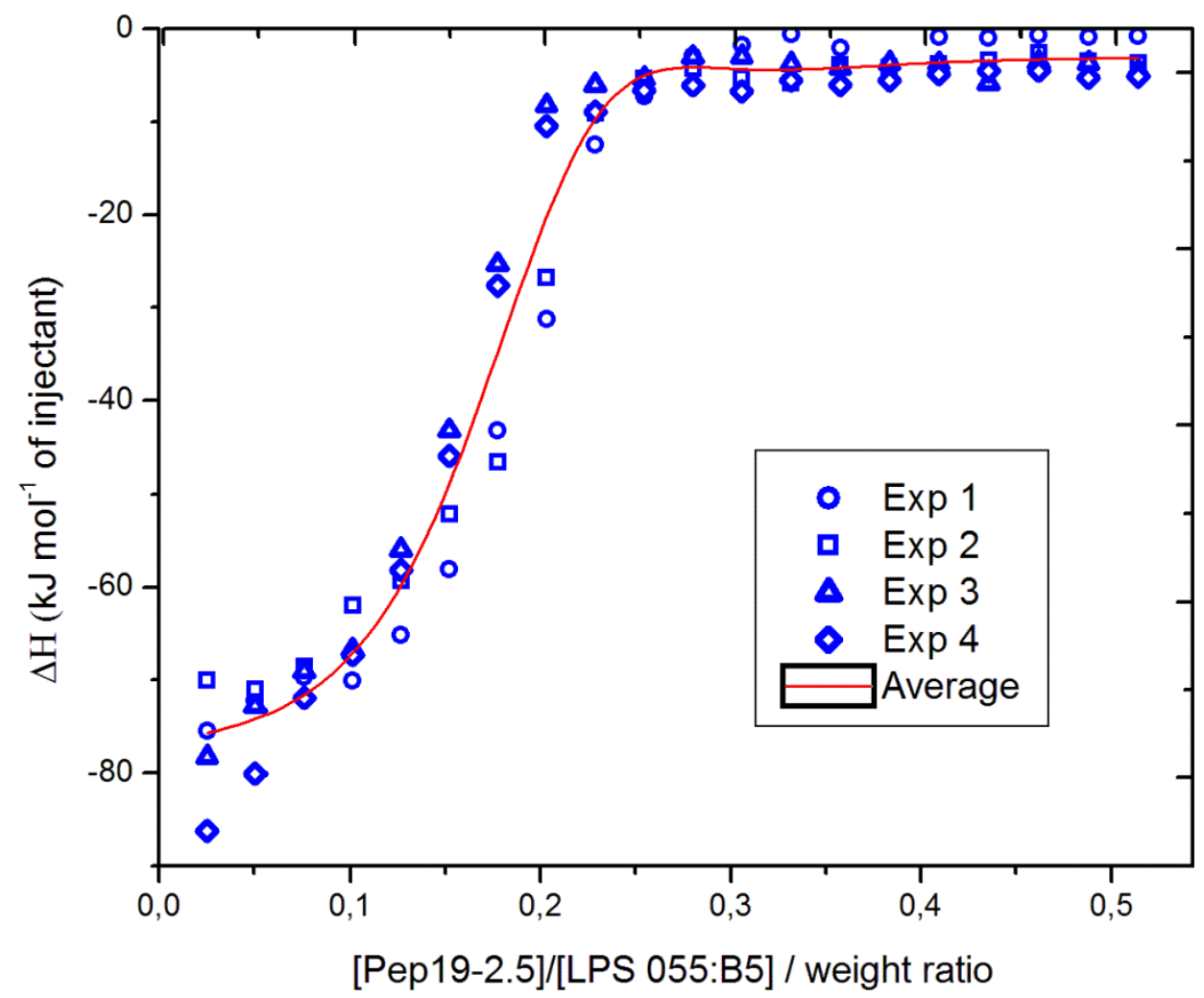

Figure 8 